\title{
Tenure and Experience Effects on Wages: A Theory
}

\author{
Ken Burdett \\ Melvyn Coles
}

CESIFO WORKING PAPER NO. 3203

CATEGORY 4: LABOUR MARKETS

OCTOBER 2010

\footnotetext{
An electronic version of the paper may be downloaded

- from the SSRN website: www.SSRN.com

- from the RePEc website: - from the CESifo website: 


\title{
Tenure and Experience Effects on Wages: A Theory
}

\begin{abstract}
This paper investigates equilibria in a labor market where firms post wage/tenure contracts and risk-averse workers, both employed and unemployed, search for better paid job opportunities. Different firms typically offer different contracts. Workers accumulate general human capital through learning-by-doing. With on-the-job search, a worker's wage evolves endogenously over time through experience effects, tenure effects and quits to better paid employment. This equilibrium approach suggests how to identify econometrically between experience and tenure effects on worker wages.
\end{abstract}

JEL-Code: J41.

Keywords: experience, tenure, search, equilibrium.

Ken Burdett

Department of Economics

University of Pennsylvania
Melvyn Coles

Department of Economics

University of Essex

mcole@essex.ac.uk

October, 2010 


\section{$1 \quad$ Introduction}

Here we investigate individual wage dynamics in the context of an equilibrium labour market framework where workers accumulate human capital while working, firms post contracts, and workers search while employed. The analysis leads to new insights into two important areas in labour economics - the nature of equilibrium in search markets, and the empirical decomposition of wages into experience and tenure effects.

There is a significant empirical literature which has attempted to decompose wages into experience and tenure effects (see, for example, Altonji and Shakotko (1987), Topel (1991), Altonji and Williams (2005), and Dustmann and Meghir (2005)). The results obtained are still hotly debated. There are two major difficulties faced by researchers in this area. First, tenure and experience are perfectly correlated within any employment spell. Second, it is unreasonable to assume a quit (which resets tenure to zero) is an exogenous outcome which is orthogonal to the wages paid by the previous employer and the new one. Without an equilibrium framework it seems an heroic task identifying between tenure and experience wage effects. A major objective of this study is to provide a coherent framework which identifies between these two factors.

The typical theoretical justification presented to explain why wages change both with experience and with tenure is based on two big ideas associated with Rosen (1972) and Mincer (1974). First, although there is no free lunch, it is accepted by many that individuals accumulate human capital by working. Typists become better typists while working as typists, economists become more productive by doing economics, etc. This seems both an important and intuitive idea. A related idea now common among labour economists, is that human capital can be dichotomized into general human capital and firm specific human capital. A worker who enjoys an increase in general human capital becomes more productive at all jobs, whereas accumulating firm specific human capital implies a worker is only more productive at that firm. Workers who change job, or those who are laid off, lose their firm specific human capital but keep their general human capital. Putting these two ideas together,

plus assuming a worker's wage is an increasing function of both his/her general and 
specific human capital, leads to at least the rudiments of a theory of how a worker's wage can depend on both experience and tenure.

The central difficulty with using this simple theory in applied work is that when the market is competitive, firm specific capital has no impact on wages and so, in the absence of any frictions, there should be no tenure effect on wages. Conversely when markets are frictional, job search yields non-trivial wage dynamics. Indeed even when there is no human capital accumulation, Burdett (1978) demonstrated some time ago that through on-the-job search, quit turnover alone could explain why the average wage of workers is a concave, increasing function of worker experience.

In the present study we describe a labour market with frictions where workers accumulate general human capital through learning-by-doing and there are also (endogenous) tenure effects. It yields a description of cross section wage dispersion which is consistent with the distribution of wage/age profiles across individual workers. The framework is particularly rich as:

(i) workers are ex-ante heterogeneous - workers have different productivities when first entering the labour market;

(ii) randomness in the job search process implies even workers of the same age may have very different work experience and thus have accumulated different levels of human capital;

(iii) there is dispersion in wage contracts offered by firms so that starting wages and tenure effects vary systematically across firms;

(iv) there is sorting with age, where on-the-job search implies older workers have, on average, better paid employment.

Even allowing for such richness, the model yields a relatively straightforward econometric structure. We discuss this structure in detail in Section 6 below. An important observation, however, is that the wage tenure effect at any given firm depends on its starting wage offer: the greater a firm's initial wage offer, the smaller the wage-tenure effect. Indeed a firm whose payrates are close to the highest in the market will have very small tenure effects. This structure also predicts that younger workers (who on average tend to be less well paid) enjoy greater wage increases with 
tenure than do older workers.

The paper builds on the seminal work of Burdett (1978) and Burdett and Mortensen (1998) which show how equilibrium search can generate wage dispersion and individual wage profiles that are (on average) increasing and concave in experience. Stevens (2004) subsequently demonstrated why, in that framework, firms increase profit by offering contracts which increase the wage paid with tenure (or seniority). Essentially paying higher wages at longer tenures rewards worker loyalty. This is profitable to the firm as rewarding loyalty reduces a worker's quit incentive and the firm can then pay lower wages at short tenures to better extract the search rents of new hires. With risk neutral workers, Stevens (2004) showed the optimal tenure contract is a step contract, say the firm pays some base wage until the worker reaches some promotion tenure $T$, after which the worker is paid marginal product. Burdett and Coles (2003) showed with strictly risk averse workers, the optimal contract smooths wage payments by tenure. It then described a search equilibrium where different firms post different optimal contracts and workers used optimal search strategies. ${ }^{1}$

Several papers have considered general human capital accumulation within the Burdett/Mortensen framework (see for example Bunzel et. al. (2000), Barlevy (2005), Burdett et al (2010)). The addition of learning-by-doing generates interesting sorting effects: higher wage firms not only attract and retain more workers, but also, in steady state, enjoy a more experienced and thus more productive workforce. The introduction of learning-by-doing also significantly increases equilibrium wage inequality: young workers not only have little work experience, the reservation wage (or piece rate) of the unemployed is low as experience is valuable and an employee will accept a low paid job as an investment in increased (future) productivity.

A complementary approach to the one taken here assumes instead firms compete on wages when an employee receives an outside offer (see for example Postel Vinay and Robin (2002a,b)). This approach yields an important econometric structure for applied work on wages and turnover. With competitive bidding by firms, turnover becomes very simple: a worker quits whenever he/she contacts a higher productivity

\footnotetext{
${ }^{1}$ More recently Shi (2009) has applied this contracting approach to the directed search framework.
} 
firm. Observed wages are then a convolution of each firm's bid function and the distribution of firm productivities: the wage paid to any given employee simply matches the value of that employee's best previous offer. Yamaguchi (2006), and Bagger et al. (2010) also extend that framework to human capital accumulation while employed.

Of course it is an empirical question whether firms match offers or not (though see Postel Vinay and Robin (2004) and Holzner (2010) who ask when this policy may, or may not be, privately optimal for firms). Clearly, in some labor markets firms do respond to outside offers (as in the academic labor market), whereas in others (as in the labor market for bricklayers) firms do not respond. The empirical implications of these two approaches are different. For example Burdett and Coles (2010) show that turnover is not efficient when firms post tenure contracts: well paid senior workers may reject job offers at more productive firms whose starting salaries are too low. Also the quit behaviour of workers is different. Here within any employment spell, a worker's quit rate decreases with tenure; i.e. at any given firm, there is negative duration dependence in its employees' job-to-job hazard rate. Conversely in a matching offers framework, a worker quits as soon as he/she contacts a higher productivity firm. In that case at any given firm, there is no duration dependence in its employees' job-tojob hazard rate. Finally the matching offers framework implies income is subject to large shocks within an employment spell: a worker may enjoy a substantial payrise by generating an outside offer. Conversely the framework here implies wages within an employment spell increase incrementally (through an internal promotion scheme).

The next Section specifies the basic framework. Section 3 characterises the set of optimal contracts offered by firms and section 4 defines a market equilibrium and describes its steady state properties. Section 5 proves the existence of a Market Equilibrium. Section 6 describes the empirical implications of this framework and concludes. 


\section{THE BASIC FRAMEWORK}

The object is to construct an equilibrium framework where the income received by an employed worker may vary with total work experience as well as with tenure. A worker's wage changes with experience as the worker becomes more productive through learning-by-doing. Further a worker's wage can vary with tenure as a result of the wage contract offered by a firm.

Time is continuous with an infinite horizon and only steady-states are considered. There is a continuum of both firms and workers, each of measure one. All firms are equally productive and have a constant returns to scale technology. A worker's life in this market is described by an exponential distribution with parameter $\phi>0$. Hence over any small time period $d t>0$, any worker leaves the market for good with probability $\phi d t$. The parameter $\phi$ also describes the inflow of new labour market entrants. Each new entrant is initally unemployed and, for the moment, we assume each has the same initial productivity $y_{0}$. Later we show that the results generalize straightforwardly to the case that workers are ex-ante heterogenous.

Learning-by-doing implies a worker's productivity increases while employed. Let $\rho>0$ denote this learning rate. Thus after $x$ years of work experience, a worker's productivity is $y=y_{0} e^{\rho x}$. We restrict our attention to $\rho<\phi$ so that lifetime payoffs are bounded. While unemployed there is no learning-by-doing but nor is there human capital decay - an unemployed worker's productivity y simply remains constant. A worker with productivity $y$ generates revenue flow $y$ while employed and income by while unemployed, where $0<b<1$.

Following Stevens (2004), firms offer optimal wage contracts where, inter alia, the wage paid depends on the employee's tenure (or seniority) $\tau .{ }^{2}$ In general firm $j$ 's employment contract is a function which pays each employee a wage $w=w_{j}(y, x, \tau)$. Clearly there is no loss in generality by focussing on piece-rate contracts $\theta=\theta_{j}(y, x, \tau)$ with wage paid $w=y \theta_{j}(y, x, \tau)$. Further as $y=y_{0} e^{\rho x}$, and experience $x=x_{0}+$

\footnotetext{
${ }^{2}$ See Stevens (2004) for a complete discussion on the structure of optimal contracts when workers are risk neutral. Note that such a contract rules out matching-offer behaviour as considered in Postel-Vinay and Robin (2002a,b).
} 
$\tau$ where $x_{0}$ is the employee's prior work experience, there is no loss in generality by further restricting attention to piece-rate tenure contracts of the form $\theta_{j}\left(\tau, x_{0}\right)$. In the absence of tenure effects and learning-by-doing, Carillo (2008) explores how conditioning wages on prior experience $x_{0}$ affects market outcomes in a frictional labour market. Here we rule out such discrimination by supposing each firm must offer the same contract to potential hires with the same productivity. Specifically firm $j$ offers the same piece rate tenure contract $\theta=\theta_{j}(\tau)$ to each new hire. Thus more experienced workers are hired at a higher starting wage $w=y \theta_{j}(0)$ but the contract is not otherwise allowed to discriminate by experience. We discuss further the role of this assumption in the conclusion.

Workers are either unemployed or employed and all obtain new job offers at Poisson rate $\lambda$, independent of their employment status. Given an employee receives an outside contract offer, say $\widetilde{\theta}(\cdot)$, the worker compares the value of remaining at his/her current firm with contract $\theta$ (.) with current tenure $\tau$, or switching to the new firm offering contract $\widetilde{\theta}(\cdot)$ with zero tenure. Any job offer received is assumed to be the realization of a random draw from the distribution of all offers made by firms. We describe this in more detail below. There are job destruction shocks in that each employed worker is displaced into unemployment according to a exponential random variable with parameter $\delta>0$. As is standard, there is no recall of previously rejected employment offers.

In the absence of job destruction shocks, workers would find their earnings always increase over time. An optimal consumption strategy with liquidity constraints would then imply workers consume current earnings $\theta(\tau) y$. Job destruction shocks, however, generate a precautionary savings motive. For tractability, however, we simplify by assuming workers can neither borrow nor save; i.e. consumption equals earnings at all points in time. We further assume a flow utility function with constant relative risk aversion; i.e. $u(w)=w^{1-\sigma} /(1-\sigma)$ with $\sigma \geq 0 .^{3}$

Firms and workers have a zero rate of time preference. Firms are also risk neutral

\footnotetext{
${ }^{3}$ as typically done, we assume the worker's continuation payoff is zero in the event of death. But note that $\sigma>1$ implies flow utility is negative and in that case we must also rule out suicide.
} 
and so the objective of each is to maximize steady state flow profit. Each worker chooses a search and quit strategy to maximize expected total lifetime utility where the exit process implies each discounts the future at rate $\phi$. Unless otherwise stated, proofs of all claims made below are presented in the technical Appendix.

\section{Workers}

Let $V=V(y, \tau \mid \theta)$ denote the maximum expected lifetime utility of an employed worker with current productivity $y$, tenure $\tau$ with piece rate contract $\theta(\cdot)$. As a contract which induces an employee to quit into unemployment is never optimal, ${ }^{4}$ an optimal contract and standard arguments imply $V($.$) satisfies:$

$$
\begin{aligned}
\phi V(y, \tau \mid \theta)= & \frac{\theta(\tau)^{1-\sigma} y^{1-\sigma}}{1-\sigma}+\rho y \frac{\partial V}{\partial y}+\frac{\partial V}{\partial \tau}+\delta\left[V^{U}(y)-V(y, \tau \mid \theta)\right] \\
& +\lambda[E \max \{V(y, \tau \mid \theta), V(y, 0 \mid \widetilde{\theta})\}-V(y, \tau \mid \theta)]
\end{aligned}
$$

where $V^{U}(y)$ denotes the maximum expected lifetime utility to an unemployed worker with productivity $y$. Note, the employee's payoff varies through time as the worker's productivity increases through learning-by-doing (picked up by the $\partial V / \partial y$ term) and as the piece rate earned varies with tenure (picked up by the $\partial V / \partial \tau$ term). Also at rate $\lambda$ the worker receives a (random) outside contract offer $\tilde{\theta}$ and quits if $V(y, 0 \mid \widetilde{\theta})>V(y, \tau \mid \theta)$. The value of being unemployed $V^{U}(y)$ satisfies

$$
\phi V^{U}(y)=\frac{(b y)^{1-\sigma}}{1-\sigma}+\lambda\left[E \max \left\{V^{U}(y), V(y, 0 \mid \widetilde{\theta})\right\}-V^{U}(y)\right]
$$

As firms pay piece rates then wages earned are always proportional to productivity $y$. Further a CRRA utility function and the assumption that productivity grows at a constant rate now imply these value functions are separable in productivity $y$; i.e. $V$

\footnotetext{
${ }^{4}$ Suppose an optimal contract implies the worker quits into unemployment at tenure $T \geq 0$. Thus at tenure $T$, the firm's continuation profit is zero and the worker obtains $V^{U}$. The same contract but which instead offers piece rate $\theta(t)=b$ for all tenures $t \geq T$ is strictly profit increasing - on-the-job learning implies the worker obtains an improved payoff no lower than $V^{U}$ at $T$ and, by not quitting, the firm's continuation payoff is strictly positive (as $b<1$ ). This latter contract then makes greater expected profit which contradicts optimality of the original contract.
} 
and $V^{U}$ take the form

$$
\begin{aligned}
V(y, \tau \mid \theta) & =y^{1-\sigma} U(\tau \mid \theta) \\
V^{U}(y) & =y^{1-\sigma} U^{U},
\end{aligned}
$$

where $U(\tau \mid \theta)$ is termed the piece rate value of contract $\theta$ (at tenure $\tau$ ) and $U^{U}$ is called the piece rate value of unemployment. ${ }^{5}$

Let $U_{0}=U(0 \mid \widetilde{\theta})$ denote the starting piece rate value of a representative contract offer $\widetilde{\theta}$. As search is random, let $F\left(\widetilde{U}_{0}\right)$ denote the fraction of firms making a contract offer whose starting piece rate value is no greater than $\widetilde{U}_{0}$. Substituting out $V(y, \tau \mid \theta)=y^{1-\sigma} U(\tau \mid \theta)$ and $V^{U}(y)=y^{1-\sigma} U^{U}$ in the Bellman equations above now yields the following equations for $U(. \mid \theta)$ and $U^{U}$ :

$$
\begin{gathered}
{[\delta+\phi-\rho(1-\sigma)] U-\frac{d U}{d \tau}=\frac{[\theta(\tau)]^{1-\sigma}}{1-\sigma}+\delta U^{U}+\lambda \int_{U}^{\bar{U}}\left[1-F\left(U_{0}\right)\right] d U_{0} .} \\
\phi U^{U}=\frac{b^{1-\sigma}}{1-\sigma}+\lambda \int_{U^{U}}^{\bar{U}}\left[U_{0}-U^{U}\right] d F\left(U_{0}\right)
\end{gathered}
$$

This has an obvious but important implication. Independent of the worker's current productivity $y$, an unemployed worker will accept offer $U_{0}$ if and only if $U_{0} \geq U^{U}$. This implies the expected duration of unemployment is the same for all workers. Further a worker's quit rate is also independent of productivity y: an employed worker with current piece rate value $U(\tau \mid \theta)$ will accept a job offer $\widetilde{\theta}$ if and only if the latter's starting piece rate value $U(0 \mid \widetilde{\theta})>U(\tau \mid \theta)$.

The above yields a complete description of optimal quit behaviour by workers: any employee with tenure $\tau$ at a firm offering contract $\theta(\cdot)$ leaves at rate $\phi+\delta+$ $\lambda[1-F(U(\tau \mid \theta))]$. Thus at the time of hiring, the probability the new hire will still be employed at the firm after any given tenure $\tau$ is

$$
\psi(\tau \mid \theta)=e^{-\int_{0}^{\tau}\{\phi+\delta+\lambda[1-F(U(s \mid \theta))]\} d s} .
$$

\footnotetext{
${ }^{5}$ Note, equilibrium will find $U(\tau \mid \theta)>0(<0)$ when $\sigma<1(>1)$ so that payoffs are always increasing in productivity $y$.
} 


\section{Firms}

Let $\overline{u e}$ denote the steady state unemployment rate and let $N(x)$ denote the fraction of unemployed workers who have experience no greater than $x$. Measure $1-\overline{u e}$ of workers are thus employed. Let $H(x, U)$ denote the proportion of employed workers who have experience no greater than $x$ and piece rate value no greater than $U$. Below we determine each of these objects (in a steady state equilibrium) but for now take them as given.

Consider a firm which posts contract $\theta($.$) with starting piece rate value U_{0}=$ $U(0 \mid \theta)$. If $U_{0}<U^{U}$ all potential employees prefer unemployment to accepting this job offer and so such an offer yields zero profit. Suppose instead $U_{0} \geq U^{U}$ - such offers are accepted at least by unemployed workers. As there is no discounting, the firm's steady state flow profit can be written as

$$
\begin{aligned}
\Omega(\theta)= & \left.\lambda \overline{u e} \int_{x=0}^{\infty}\left[\int_{0}^{\infty} \psi(\tau \mid \theta)\right)[1-\theta(\tau)] e^{\rho \tau}\left[y_{0} e^{\rho x}\right] d \tau\right] d N(x) \\
& +\lambda(1-\overline{u e}) \int_{U^{\prime}=\underline{U}}^{U_{0}} \int_{x=0}^{\infty}\left[\int_{0}^{\infty} \psi(\tau \mid \theta)[1-\theta(\tau)] e^{\rho \tau}\left[y_{0} e^{\rho x}\right] d \tau\right] d H\left(x, U^{\prime}\right) .
\end{aligned}
$$

The firm's steady state flow profit is composed of two terms. The first term describes the hiring inflow of unemployed workers by experience $x$ (with corresponding initial productivity $\left.y=y_{0} \exp (\rho x)\right)$ times the expected profit obtained by employing such a worker. The second term describes the hiring inflow of currently employed workers by experience $x$ and (outside) value $U^{\prime}$ (where a worker on piece rate value $U^{\prime}$ will only accept the job offer if $U^{\prime}<U_{0}$ ) times the expected profit per each type of hire. Simple manipulation establishes

$$
\Omega(\theta)=\lambda\left[\overline{u e} \int_{x=0}^{\infty} y_{0} e^{\rho x} d N(x)+(1-\overline{u e}) \int_{U^{\prime}=\underline{U}}^{U_{0}} \int_{x=0}^{\infty} y_{0} e^{\rho x} d H\left(x, U^{\prime}\right)\right]\left[\int_{0}^{\infty} \psi(t \mid \theta)[1-\theta(t)] e^{\rho t} d t\right] .
$$

Note the first bracketed term depends only on $U_{0}$ (given $\overline{u e}, N, H$ ).

To determine the contract that maximizes $\Omega$ we use the following two step procedure. First we identify a firm's piece rate contract which maximizes

$$
\int_{0}^{\infty} \psi(t \mid \theta(.))[1-\theta(t)] e^{\rho t} d t
$$


conditional on the contract yielding piece rate value $U_{0}$. Such a contract is termed an optimal contract and is denoted $\theta^{*}\left(. \mid U_{0}\right)$. We can then define maximized profit per hire

$$
\Pi^{*}\left(0 \mid U_{0}\right)=\int_{0}^{\infty} \psi\left(t \mid \theta^{*}\right)\left[1-\theta^{*}\left(t \mid U_{0}\right)\right] e^{\rho t} d t
$$

An optimal contract thus yields steady-state flow profits

$$
\Omega^{*}\left(U_{0}\right)=\lambda y_{0}\left[\overline{u e} \int_{x=0}^{\infty} e^{\rho x} d N(x)+(1-\overline{u e}) \int_{U^{\prime}=\underline{U}}^{U_{0}} \int_{x=0}^{\infty} e^{\rho x} d H\left(x, U^{\prime}\right)\right] \Pi^{*}\left(0 \mid U_{0}\right) .
$$

The firm's optimization problem then reduces to choosing a starting payoff $U_{0}$ to maximize $\Omega^{*}\left(U_{0}\right)$. Before formally defining an equilibrium, it is convenient first to characterise the set of optimal contracts $\theta^{*}$ for any given distribution functions $F, N$ and $H$.

\section{Optimal Piece Rate Tenure Contracts.}

In this Section we extend the arguments used in Burdett and Coles (2003) to a more general setting. A useful preliminary insight is that as the arrival rate of offers is independent of a worker's employment status, an unemployed worker will always accept a contract which offers $\theta(\tau)=b$ for all $t$. Further, as $b<1$ by assumption, a firm can always obtain strictly positive profit by offering this contract. Thus, without loss of generality, we make the following restrictions: all firms make strictly positive profit; i.e., $\Omega^{*}>0$, and $\underline{U} \geq U^{U}$, i.e., all firms make acceptable offers. To simplify the exposition further, however, we also assume $F$ has a connected support.

For any starting value $U_{0} \geq U^{U}$, an optimal contract $\theta^{*}\left(. \mid U_{0}\right)$ solves the program

$$
\max _{\theta(.)} \int_{0}^{\infty} \psi(t \mid \theta(.)) e^{\rho t}[1-\theta(t)] d t
$$

subject to (a) $\theta() \geq$.0 , (b) $U(0 \mid \theta())=.U_{0}$ and (c) the optimal quit strategies of workers which determine the survival probability $\psi(. \mid \theta)$. As $\sigma>0$ implies the marginal utility of consumption is infinite at $\theta=0$, we will show an optimal contract always implies $\theta>0$ for all $t>0$. 
Given an optimal contract $\theta^{*}$ which yields starting value $U_{0}$, let $U^{*} \equiv U\left(\tau \mid \theta^{*}\right)$ denote the worker's piece rate value of employment at tenure $\tau$ and note we can describe $U^{*}$ as $U^{*}\left(\tau \mid U_{0}\right)$. Similarly given an optimal contract $\theta^{*}$ which yields starting value $U_{0}$, let $\Pi^{*}\left(\tau \mid U_{0}\right)$ denote the firm's continuation value at tenure $\tau$; i.e.

$$
\Pi^{*}\left(\tau \mid U_{0}\right)=\int_{\tau}^{\infty} e^{-\int_{\tau}^{t}\left[\delta+\phi-\rho+\lambda\left(1-F\left(U^{*}\left(s \mid U_{0}\right)\right)\right] d s\right.}\left[1-\theta^{*}\left(t \mid U_{0}\right)\right] d t .
$$

Theorem 1. For any $U_{0} \geq \underline{U}$, an optimal contract $\theta^{*}\left(. \mid U_{0}\right)$ and corresponding worker and firm payoffs $U^{*}$ and $\Pi^{*}$ are solutions to the dynamical system $\{\theta, U, \Pi\}$ where (a) $\theta$ is determined by

$$
\begin{aligned}
& \frac{\theta^{1-\sigma}}{1-\sigma}+\theta^{-\sigma}[1-\theta+[\rho-\phi-\delta-\lambda(1-F(U))] \Pi] \\
= & {[\delta+\phi-\rho(1-\sigma)] U-\delta U^{U}-\lambda \int_{U}^{\bar{U}}\left[1-F\left(U_{0}\right)\right] d U_{0} . }
\end{aligned}
$$

(b) $\Pi$ is given by

$$
\Pi(t)=\int_{t}^{\infty} e^{-\int_{t}^{s}[\delta+\phi-\rho+\lambda(1-F(U(\tau))] d \tau}(1-\theta(s)) d s, \text { and }
$$

(c) $U$ evolves according to the differential equation

$$
\frac{d U}{d t}=-\theta^{-\sigma} \frac{d \Pi}{d t}
$$

with initial value $U(0)=U_{0}$.

The above characterization of an optimal contract is very general - it allows for mass points in $F$ and the density of $F$ need not exist. In the equilibrium described in Theorem 3 below, however, the density of offers $F^{\prime}$ exists. In that case, a more intuitive structure arises if we totally differentiate (5) and (6) with respect to $t$ and so obtain the following differential equation system for $(\theta, \Pi, U)$ :

$$
\begin{gathered}
\dot{\theta}=\frac{\lambda\left[\theta^{1-\sigma}\right]}{\sigma} F^{\prime}(U) \Pi-\rho \theta \\
\dot{\Pi}=[\delta+\phi-\rho+\lambda(1-F(U))] \Pi-(1-\theta) \\
\dot{U}=-\theta^{-\sigma} \dot{\Pi}
\end{gathered}
$$


(8) describes how piece rates change along the optimal piece rate contract. If workers are risk neutral $(\sigma=0)$, as in Stevens (2004), the optimal contract is to pay $\theta=0$ for a finite spell $\tau<T$, after which the worker is paid marginal product, $\theta=1$. The reason is that an employee who is paid less than marginal product is likely to be poached by a better paying competitor. When the worker is risk neutral, the firm extracts the search rents of new hires as quickly as possible by paying the floor wage $w=0$. When instead workers are strictly risk averse $(\sigma>0)$, workers prefer a smoother consumption profile. The optimal contract then involves a trade-off between lower wage variation (smoother consumption) and reducing worker quit incentives.

The wage received within the employment spell is $\theta(\tau) e^{\rho \tau}\left[y_{0} e^{\rho x_{0}}\right]$, where $x_{0}$ describes the worker's prior experience when hired by the firm. Thus (8) implies the wage received evolves according to

$$
\frac{\frac{d}{d t}\left[y_{0} e^{\rho x_{0}} e^{\rho t} \theta(t)\right]}{y_{0} e^{\rho x_{0}} e^{\rho t} \theta(t)}=\frac{\lambda F^{\prime}(U) \Pi}{\sigma \theta^{\sigma}} .
$$

Wages are thus always increasing within an employment spell, and strictly increasing when the density of competing outside offers is positive (i.e., $F^{\prime}(U)>0$ ). The optimal contract reveals the underlying trade-off between lower wage variation (smoother consumption) and reducing the marginal quit incentives of employees: $F^{\prime}(U)$ describes the marginal number of competing firms who might attract employee on value $U$, and $\Pi$ describes the firm's corresponding loss in profit should this employee quit. Note further that a constant wage (perfect consumption smoothing) requires a piece rate $\theta(\tau)$ which declines at rate $\rho$. Thus even though an optimal contract implies wages must always increase within an employment spell, tenure effects may now be negative (but not so large that wages paid decline).

Assuming $F^{\prime}$ exists, the optimal piece rate contract is the saddle path solution to the differential equation system (8)-(10). Let $\left(\theta^{\infty}, \Pi^{\infty}, U^{\infty}\right)$ denote the stationary point of the dynamical system (8)-(10); i.e. $\left(\theta^{\infty}, \Pi^{\infty}, U^{\infty}\right)$ solves:

$$
\begin{gathered}
{\left[\theta^{\infty}\right]^{\sigma}=\frac{\lambda}{\rho \sigma} F^{\prime}\left(U^{\infty}\right) \Pi^{\infty}} \\
\Pi^{\infty}=\frac{1-\theta^{\infty}}{\delta+\phi-\rho+\lambda\left(1-F\left(U^{\infty}\right)\right)} .
\end{gathered}
$$


There are two types of optimal contracts; those whose piece rate value converges to $U^{\infty}$ from above and those whose value converge to $U^{\infty}$ from below. Figure 1 depicts the corresponding contracts $\theta^{*}($.$) in tenure space.$

Consider first the optimal contract for the firm offering the least generous contract, i.e., $U_{0}=\underline{U}$. Further, assume $\underline{U}<U^{\infty}$. As shown in Figure 1, optimal $\theta(.) \equiv \theta^{s 1}($. increases with tenure and converges to the limit value $\theta^{\infty}$. As piece rates increase with tenure, it follows $U \equiv U^{s 1}$ increases with tenure (and converges to $U^{\infty}$ ) (while continuation profit $\Pi$ decreases with tenure and converges to $\left.\Pi^{\infty}\right)$. Consider now the optimal contract offered by firms offering the most generous contract, i.e., $U_{0}=$ $\bar{U}$. Further, assume $\bar{U}>U^{\infty}$. Although the wage paid increases with tenure, the corresponding piece rate $\theta(.) \equiv \theta^{s 2}($.$) decreases with tenure and converges to \theta^{\infty}$ from above. This is also illustrated in Figure 1. The two optimal contracts, $\theta^{s 1}($. and $\theta^{s 2}($.$) , defined above will be termed the lower and upper baseline piece rate scales$ respectively. 


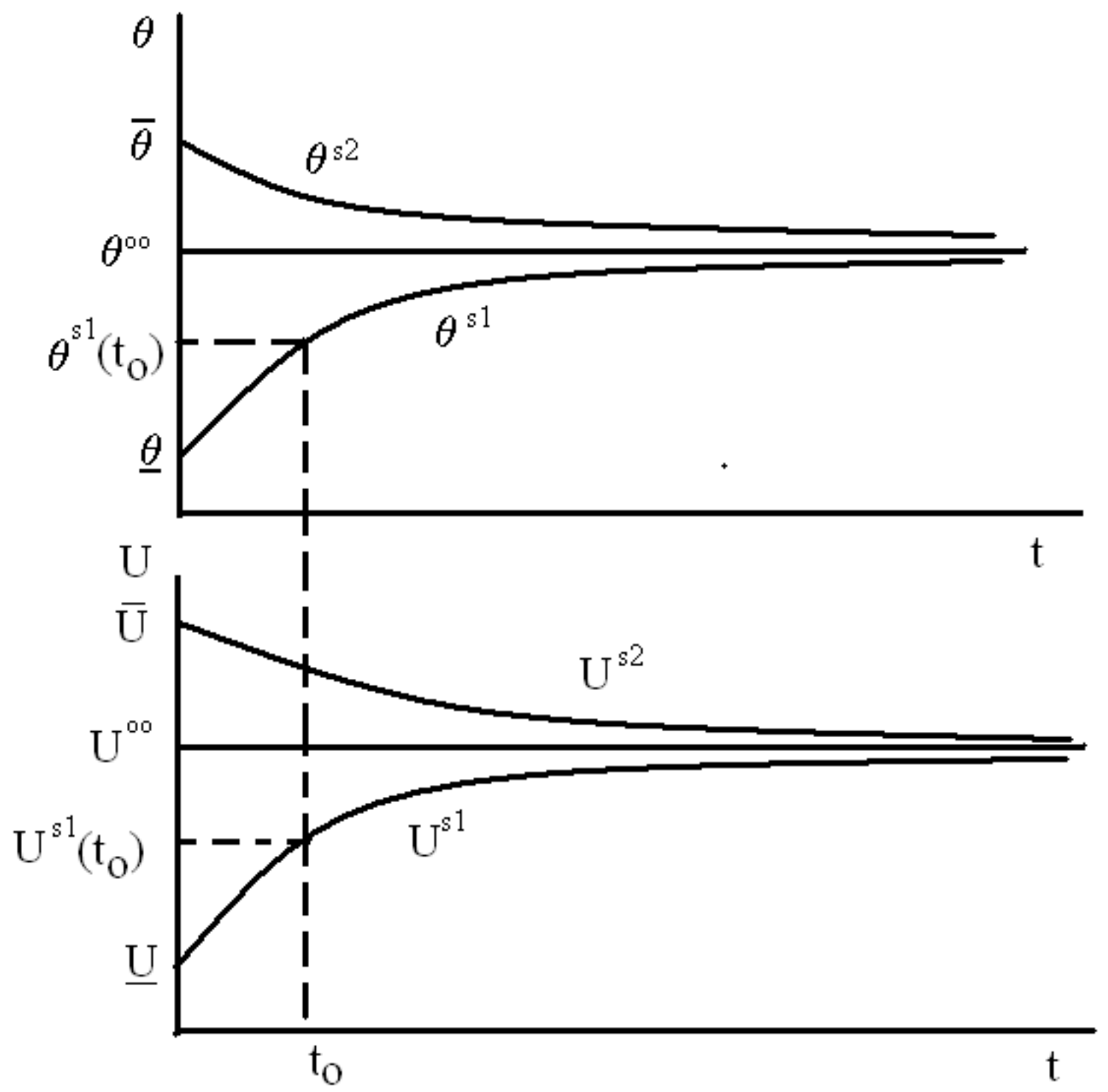

Figure 1: Baseline Piece Rate Scales

Consider now a firm that offers a contract which yields an initial piece rate value $U_{0}$ such that $\underline{U}<U_{0}<U^{\infty}$. As depicted in Figure 1, define $t_{0}$ as the point on the lower baseline contract where $U^{s 1}\left(t_{0}\right)=U_{0}$. Optimality of the lower baseline piece rate scale now yields a major simplification: the optimal contract yielding this $U_{0}$ is simply the continuation contract starting at point $t_{0}$ on the lower baseline piece rate 
scale; i.e., the optimal contract $\theta^{*}\left(\tau \mid U_{0}\right)$ is $\theta^{s 1}\left(t_{0}+\tau\right)$ where the piece rate paid at tenure $\tau$ corresponds to point $\left(t_{0}+\tau\right)$ on the lower baseline piece rate scale. Suppose instead $\bar{U}>U_{0}>U^{\infty}$. This time the optimal contract yielding $U_{0}$ is the continuation contract starting at point $t_{0}$ on the upper baseline piece rate scale where $U^{s 2}\left(t_{0}\right)=U_{0}$.

Thus for any $U_{0} \in\left[\underline{U}, U^{\infty}\right]$, the optimal contract can be described by $\theta^{s 1}($.$) and a$ starting time $t_{0} \geq 0$. Further for $U_{0} \in\left[U^{\infty}, \bar{U}\right]$, the optimal contract can be described by $\theta^{s 2}($.$) and a starting time t_{0} \geq 0$. Hence, the distribution of optimal contracts with $U_{0} \in[\underline{U}, \bar{U}]$ can be described by $\left(\theta^{s 1}(),. \Psi^{1}(),. \theta^{s 2}(),. \Psi^{2}().\right)$ where $\Psi^{i}$ is the distribution of starting times associated with $\theta^{s i}($.$) .$

Of course it may happen that $\bar{U}=U^{\infty}$ in which case only the lower baseline scale exists. In fact we shall show this is a consequence of a Market Equilibrium which we now define.

\section{MARKET EQUILIBRIUM}

Above we have shown for any $U_{0} \in[\underline{U}, \bar{U}]$ an optimal contract corresponds to a saddle path solution to the differential equation system (8)-(10). In what follows, however, equation (5) in Theorem 1 is much more useful as it describes the solution to the differential equation (8).

For any starting value $U_{0} \in[\underline{U}, \bar{U}]$, the optimal contract corresponds to a starting point $t_{0}$ on one of the piece rate scales where $U^{s i}\left(t_{0}\right)=U_{0}$, with corresponding maximized profit $\Pi^{s i}\left(t_{0}\right)$ and piece rate paid $\theta^{s i}\left(t_{0}\right)$. By substituting out $t_{0}$, we can thus define $\theta=\widehat{\theta}\left(U_{0}\right)$ as the piece rate paid when the worker enjoys $U_{0}$ on the baseline piece rate scales, and $\Pi=\widehat{\Pi}\left(U_{0}\right)$ as the firm's continuation profit. Using the conditions of Theorem 1, Claim 1 identifies $\widehat{\Pi}(U)$ and $\widehat{\theta}(U)$. 


\section{Claim 1}

For $U \in[\underline{U}, \bar{U}], \widehat{\Pi}$ evolves according to the differential equation

$$
\frac{d \widehat{\Pi}}{d U}=-\widehat{\theta}^{\sigma}
$$

while $\widehat{\theta}$ satisfies

$$
\begin{aligned}
& \frac{[\widehat{\theta}]^{1-\sigma}}{1-\sigma}+\widehat{\theta}^{-\sigma}[1-\widehat{\theta}+[\rho-\phi-\delta-\lambda(1-F(U))] \widehat{\Pi}] \\
= & {[\delta+\phi-\rho(1-\sigma)] U-\delta U^{U}-\lambda \int_{U}^{\bar{U}}\left[1-F\left(U_{0}\right)\right] d U_{0} . }
\end{aligned}
$$

Proof: This follows directly from Theorem 1 and the definitions of $\widehat{\theta}$ and $\widehat{\Pi}$.

By construction, each firm's optimized steady state flow profit by offering $U_{0} \in$ $[\underline{U}, \bar{U}]$ is

$$
\Omega^{*}\left(U_{0}\right)=\lambda \widehat{\Pi}\left(U_{0}\right)\left[\overline{u e} \int_{x=0}^{\infty} y_{0} e^{\rho x} d N(x)+(1-\overline{u e}) \int_{U^{\prime}=\underline{U}}^{U_{0}} \int_{x=0}^{\infty} y_{0} e^{\rho x} d H\left(x, U^{\prime}\right)\right] .
$$

We now formally define a Market Equilibrium.

A Market Equilibrium is a distribution of optimal contract offers, with corresponding value distribution $F(U)$, such that optimal job search by workers and steady state turnover implies the constant profit condition:

$$
\begin{aligned}
& \Omega^{*}\left(U_{0}\right)=\bar{\Omega}>0 \text { if } d F\left(U_{0}\right)>0, \\
& \Omega^{*}\left(U_{0}\right) \leq \bar{\Omega}, \text { otherwise, }
\end{aligned}
$$

The constant profit condition requires that all optimal contracts $U_{0}$ which are offered by firms in an equilibrium must make the same profit $\bar{\Omega}>0$, and all other contracts must make no greater profit. Below for any distribution of contract offers $F$, we first use steady state turnover arguments to determine the equilibrium unemployment rate $\overline{u e}$ and distribution functions $N$ and $H$. Identifying a Market Equilibrium then requires finding $F($.$) so that the above constant profit condition is satisfied. We$ perform this task using a series of lemmas. Lemma 1 describes a standard result. 
Lemma 1. A Market Equilibrium implies:

(a) $\underline{U}=U^{u}$

(b) $\overline{u e}=(\phi+\delta) /(\lambda+\phi+\delta)$.

Part (a) establishes that the lowest value offer $\underline{U}$ extracts all search rents from the unemployed. Part (b) identifies the steady state unemployment rate given all unemployed workers accept their first job offer.

With Lemma 1 in hand, we can now characterize steady state $N(x)$ and $H(x, U)$. As all unemployed workers accept the first job offer received, and employed workers never quit into unemployment, obtaining the steady state distribution of experience across unemployed workers is straightforward. Standard turnover arguments establish

$$
N(x)=1-\frac{\lambda \delta}{(\phi+\lambda)(\phi+\delta)} e^{-\frac{\phi(\phi+\delta+\lambda) x}{(\phi+\lambda)}} .
$$

Let $N_{0}=N(0)$ which describes the proportion of unemployed workers who have never had a job and so have zero experience. (18) implies $N_{0}>0$. For $x>0$, the distribution of experience across unemployed worker is described by the exponential distribution.

Standard turnover arguments also establish that the distribution of experience across all employed workers is

$$
H(x, \bar{U})=1-e^{-\frac{\phi(\phi+\delta+\lambda) x}{(\phi+\lambda)}} .
$$

In contrast to $N$, note that $H(0, \bar{U})=0$ : in a steady state the measure of employed workers with zero experience must be zero. Lemma 2 now characterizes $H($.$) for all$ $x>0, U \in[\underline{U}, \bar{U}]$.

Lemma 2. For $x>0$ and $U \in[\underline{U}, \bar{U}], H=H(x, U)$ satisfies the partial differential equation:

$$
[\phi+\delta+\lambda(1-F(U))] H+\frac{\partial H}{\partial x}+\dot{U} \frac{\partial H}{\partial U}=(\phi+\delta) F(U) N(x),
$$

where along the baseline piece rate scale $\dot{U}=\dot{U}(U)$ is given by:

$$
\dot{U}=\widehat{\theta}^{-\sigma}[(1-\widehat{\theta})-[\delta+\phi-\rho+\lambda(1-F(U))] \widehat{\Pi}]
$$


and $H$ satisfies the boundary conditions

$$
\begin{aligned}
& H(0, U)=0 \text { for all } U \in[\underline{U}, \bar{U}] ; \\
& H(x, \underline{U})=0 \text { for all } x \geq 0 .
\end{aligned}
$$

Although $H$ is described by a relatively straightforward first order partial differential equation, a closed form solution does not exist. Nevertheless it is still possible to characterize fully a Market Equilibrium.

Substituting out $\overline{u e}$ (obtained in Lemma 1) and $N(x)$ (given by (18)) in (16), straightforward algebra implies the constant profit condition requires finding an $F$ such that

$\widehat{\Pi}\left(U_{0}\right)\left[\frac{\phi(\phi+\delta-\rho)}{\phi(\phi+\delta+\lambda)-\rho(\phi+\lambda)}+\frac{\lambda}{\lambda+\phi+\delta} \int_{U^{\prime}=\underline{U}}^{U_{0}} \int_{x^{\prime}=0}^{\infty} e^{\rho x^{\prime}} \frac{\partial^{2} H\left(x^{\prime}, U^{\prime}\right)}{\partial x \partial U^{\prime}} d x^{\prime} d U^{\prime}\right]=\frac{\bar{\Omega}}{\lambda y_{0}}$

for all $U_{0} \in[\underline{U}, \bar{U}]$, with $H$ given by Lemma 2. By solving for the last term in the square bracket above, the proof of Theorem 2 shows the constant profit condition reduces to the following simple condition.

Theorem 2. In any Market Equilibrium, the constant profit condition is satisfied if and only if

$$
\widehat{\Pi}=\frac{1}{\phi+\delta-\rho} \sqrt{(1-\bar{\theta})(1-\widehat{\theta})} \text { for all } U_{0} \in[\underline{U}, \bar{U}]
$$

where $\bar{\theta}=\widehat{\theta}(\bar{U})$ is the highest piece rate offered in the market.

Putting $\rho=0$ finds this solution is the same as that found in Burdett and Coles (2003). Here of course, the Market Equilibrium depends on the rate of learning-bydoing.

\section{Existence and Characterization of a Market Equi- librium.}

The approach to solving for a Market Equilibrium is to hypothesize an equilibrium value for $\bar{\theta}$ and then use backward induction to map out the equilibrium outcomes. 
The free choice of $\bar{\theta}$ is then tied down by the requirement $U^{U}=\underline{U}$ (Lemma 1a).

Conditional on an equilibrium value for $\bar{\theta}$, Lemma 3 now determines the corresponding equilibrium support of offers $[\underline{U}, \bar{U}]$ and finds the (unique) closed form solution for equilibrium $\widehat{\theta}($.$) .$

Lemma 3. For any equilibrium value $\bar{\theta} \in(0,1)$, a Market Equilibrium implies $\widehat{\theta}($. is given by the implicit function

$$
\frac{\sqrt{(1-\bar{\theta})}}{2(\phi+\delta-\rho)} \int_{\widehat{\theta}}^{\bar{\theta}} \frac{1}{\left(1-\theta^{\prime}\right)^{1 / 2}\left[\theta^{\prime}\right]^{\sigma}} d \theta^{\prime}=[\bar{U}-U]
$$

for all $U \in[\underline{U}, \bar{U}]$ where $\bar{U}, \underline{U}$ satisfy

$$
\begin{gathered}
\frac{[\bar{\theta}]^{1-\sigma}}{1-\sigma}=[\phi-\rho(1-\sigma)] \bar{U}+\delta[\bar{U}-\underline{U}] \\
(1-\underline{\theta})=\left[\frac{\phi+\delta-\rho+\lambda}{\phi+\delta-\rho}\right]^{2}(1-\bar{\theta})
\end{gathered}
$$

and $\underline{\theta} \equiv \widehat{\theta}(\underline{U})$ is the lowest piece rate paid in the market; i.e.,

$$
\frac{\sqrt{(1-\bar{\theta})}}{2(\phi+\delta-\rho)} \int_{\underline{\theta}}^{\bar{\theta}} \frac{1}{\left(1-\theta^{\prime}\right)^{1 / 2}\left[\theta^{\prime}\right]^{\sigma}} d \theta^{\prime}=\bar{U}-\underline{U} .
$$

Lemma 3 establishes the following important corollary.

Corollary: A Market Equilibrium implies $\bar{U}=U^{\infty}$.

The higher baseline piece rate scale in Figure 1 implied piece rates paid might (optimally) fall with tenure. A Market Equilibrium, however, rules out this possibility. In particular lemma 3 establishes that equilibrium $\widehat{\theta}$ must satisfy (23) and differentiation implies

$$
\frac{\widehat{d \theta}}{d U}=2(\phi+\delta-\rho) \bar{\theta}^{\sigma}
$$

at $U=\bar{U}$ and so is finite. Conversely optimal contracting implies $\widehat{\theta}$ must satisfy (15) and differentiation finds

$$
\frac{d \widehat{\theta}}{d U}=\frac{\lambda\left[\bar{\theta}^{1-\sigma}\right]}{\bar{\theta}^{-\sigma}[1-\bar{\theta}-[\delta+\phi-\rho] \bar{\Pi}]}
$$


at $U=\bar{U}$. As Theorem 2 implies $\bar{\Pi}=\widehat{\Pi}(\bar{U})=(1-\bar{\theta}) /(\phi+\delta-\rho)$, the denominator in the above equation is therefore zero. Hence finiteness requires the numerator must also be zero; i.e. $\lambda \bar{\theta}^{1-\sigma} F^{\prime}(\bar{U}) \bar{\Pi} / \sigma=\rho \bar{\theta}$. This immediately implies $d \theta / d t=d U / d t=$ $d \Pi / d t=0$ at $\bar{U}$ and so $\bar{U}=U^{\infty}$.

It is now straightforward to establish existence of a Market Equilibrium. Note that $\underline{\theta} \geq 0$ and (25) imply the relevant case is $\bar{\theta} \geq 1-\left[\frac{\phi+\delta-\rho}{\phi+\delta-\rho+\lambda}\right]^{2}$. Conditional on an equilibrium value $\bar{\theta} \in\left(1-\left[\frac{\phi+\delta-\rho}{\phi+\delta-\rho+\lambda}\right]^{2}, 1\right)$, it is trivial to show a solution to the equations in Lemma 3 for $\widehat{\theta}, \underline{U}, \bar{U}$ always exists, is unique, is continuous in $\bar{\theta}$ and implies $0<\underline{\theta}<\bar{\theta}$ and $\underline{U}<\bar{U}$. Note that Theorem 2 then uniquely determines equilibrium $\widehat{\Pi}($.$) . To determine equilibrium F$, define the surplus function

$$
S(U)=\int_{U}^{\bar{U}}\left[1-F\left(U^{\prime}\right)\right] d U^{\prime}
$$

As $U^{U}=\underline{U}$ in a Market Equilibrium, (15) implies equilibrium $S$ is determined by the linear differential equation

$$
\frac{[\widehat{\theta}]^{1-\sigma}}{1-\sigma}+\widehat{\theta}^{-\sigma}\left[1-\widehat{\theta}+\left[\rho-\phi-\delta+\lambda \frac{d S}{d U}\right] \widehat{\Pi}\right]=[\delta+\phi-\rho(1-\sigma)] U-\delta \underline{U}-\lambda S
$$

for all $U \in[\underline{U}, \bar{U}]$ with initial value $S(\bar{U})=0$. Using the solutions above for $\widehat{\theta}, \widehat{\Pi}$,and $\underline{U}$, and noting Theorem 2 implies $\widehat{\Pi} \geq(1-\bar{\theta}) /(\phi+\delta-\rho)>0$, this initial value problem uniquely determines $S$, and thus $F(U)$. The final step, then, is to note a Market Equilibrium must also satisfy $U^{U}=\underline{U}$ where $U^{U}$ is given by (2). This identifies a fixed point problem which ties down the equilibrium value of $\bar{\theta}$.

Theorem 3. [Existence and Characterization]. For $\sigma>0$, a Market Equilibrium exists characterised by a $\bar{\theta} \in\left(1-\left[\frac{\phi+\delta-\rho}{\phi+\delta-\rho+\lambda}\right]^{2}, 1\right)$ with

(A) the support of offers $[\underline{U}, \bar{U}]$ (and corresponding $\underline{\theta}$ ) given by (24)-(25), where over that support,

(B) $\widehat{\theta}($.$) is given by (23), \widehat{\Pi}($.$) is given by (22), S($.$) is the solution to the initial value$ problem $(26)$ with $S(\bar{U})=0$;

(C) $U^{U}$ is given by (2) and satisfies $U^{U}=\underline{U}$. 


\section{Empirical Implications and Conclusion}

The analysis generalizes straightforwardly to the case that workers are heterogenous. In particular note that the equilibrium characterization in Theorem 3 does not depend on $y_{0}$. Assume instead then that each new entrant has productivity $y_{0}$ drawn from some population distribution $A$. Theorem 3 continues to describe the Market Equilibrium: all workers continue to use the same turnover strategies, the unemployment rate and distribution of experience is the same for each type $y_{0}$, and the equilibrium set of optimal piece rate contracts is unchanged. The only difference is that steady state flow profit is now

$\Omega^{*}\left(U_{0}\right)=\lambda \widehat{\Pi}\left(U_{0}\right) \int_{\underline{y}}^{\bar{y}}\left[\overline{u e} \int_{x=0}^{\infty} y_{0} e^{\rho x} d N(x)+(1-\overline{u e}) \int_{U^{\prime}=\underline{U}}^{U_{0}} \int_{x=0}^{\infty} y_{0} e^{\rho x} d H\left(x, U^{\prime}\right)\right] d A\left(y_{0}\right)$

for all $U_{0} \in[\underline{U}, \bar{U}]$. By defining $\mu=\int_{\underline{y}}^{\bar{y}} y_{0} d A\left(y_{0}\right)$, all the previous arguments go through but with $y_{0}$ now replaced by $\mu$.

Although a trivial theoretical extension, the extension to worker heterogeneity is clearly crucial for empirical work. If $y_{i}$ denotes the initial productivity of worker $i$, then a Market Equilibrium implies the wage earned by this worker after $x$ years experience, with tenure $\tau$ at firm $\mathrm{j}$ offering contract $\theta_{j}($.$) is:$

$$
\log w_{i j}(x, \tau)=\log y_{i}+\log \theta_{j}(0)+\rho x+\log \frac{\theta_{j}(\tau)}{\theta_{j}(0)} .
$$

The observed wage thus depends on the worker fixed effect $\log y_{i}$, the firm fixed effect $\log \theta_{j}(0)$ (which describes firm $j^{\prime} s$ starting piece rate paid to new hires), experience effect $x$ and the tenure effect at firm $j$. Of course a Market Equilibrium not only identifies the distribution of starting piece rates $\theta_{j}(0)$ across all firms $j$, it also determines the within-firm tenure effects $\theta_{j}(\tau) / \theta_{j}(0)$.

In contrast Altonji and Williams (2005) points out that, in the applied literature, the standard wage regression equation is of the form

$$
\log w_{i j}(x, \tau)=\rho x+\beta_{2} \tau+\varepsilon_{i j t}
$$


where $\beta_{2}$ measures the return to tenure and the error term

$$
\varepsilon_{i j t}=y_{i}+\phi_{i j}+u_{i t}+\nu_{i j t}
$$

contains both a worker fixed effect $y_{i}$ and a random match payoff $\phi_{i j}$ between worker $i$ and firm $j$. The remaining error terms suppose these key residuals might vary randomly over time.

A key difference between these two approaches is that the wage equation (28) contains a firm fixed effect, $\log \theta_{j}(0)$. This fixed effect is central to our explanation of quit turnover: a quit occurs whenever an employee at firm $j$ on piece rate $\theta_{j}(\tau)$ receives an outside offer from a different firm $k$ which offers starting piece rate $\theta_{k}(0)>$ $\theta_{j}(\tau)$.

The standard empirical approach instead assumes there is unobserved match heterogeneity. The difficulty then is that with endogenous quit turnover, the unobserved match value is positively correlated with experience and tenure: the former as workers with long experience have had more time to find a good match, the latter as matches with high value are likely to survive to long tenures. Controlling for this endogeneity problem is clearly problematic (see for example the classic papers Topel (1991), Altonji and Shakotko (1991) and more recently Dustmann and Meghir (2005) which identifies the return to experience by instead focussing on workers laid-off through plant closure).

An additional empirical issue is that the estimated return to tenure, $\beta_{2}$ above, is assumed to be firm-independent. The theory here not only shows this is unlikely but numerical examples find the (firm specific) tenure effect on wages is always negatively correlated with the firm fixed effect; i.e. tenure effects are larger at low wages. Or in other words, the (lower) baseline piece rate scale is concave (as drawn in Figure 1).

There seem to be two principal reasons for this. First, note that optimal contracting implies wages evolve according to (11), i.e

$$
\frac{d}{d t} \log (w(t))=\frac{\lambda F^{\prime}(U) \Pi}{\sigma \theta^{\sigma}}
$$

within an employment spell. Firms which offer a lower starting piece rate enjoy a higher expected profit per new hire $\Pi$ (but in equilibrium attract fewer hires). (29) 
implies greater profit $\Pi$ implies wages rise more quickly with tenure: the firm has a greater incentive not to lose the worker to an outside offer. Second, numerical work always finds that the equilibrium job offer distribution is tightly bunched at the lower end of the distribution. Indeed there is always a mass of firms which offer $U=\underline{U}$. Strong competition for workers at the bottom end of the wage distribution again leads firms to raise wages relatively quickly with tenure. Of course when the worker's earned piece rate is close to the top end of the distribution, and so the worker is unlikely to receive a more favourable outside offer, there is little incentive for the firm to keep raising its piece rate paid.

The approach taken here also yields a theory of cross section wage dispersion which is consistent with the distribution of wage/age profiles across individual workers. Specifically the model has an overlapping generation structure - where different individuals enter the labour market at different dates - and heterogeneous outcomes where an individual's wage depends not only on accumulated experience but also on luck in finding well paid employment. Equilibrium turnover implies interesting sorting effects: higher wage firms not only attract and retain more workers, but also, in steady state, enjoy a more experienced and thus more productive workforce (see Burdett et al (2010)). Of course these sorting effects have a direct impact on equilibrium contract competition. Such sorting also significantly increases wage inequality: young workers not only have little work experience, they also typically earn low piece rates as starting offers are rarely generous and internal promotion takes time. Indeed reservation piece rate (values) of the unemployed are particularly low as (i) experience is valuable and an employee can still search for better paid employment while employed, and (ii) expectations of promotion within a firm generates a "foot-in-the-door" effect as described in Burdett and Coles (2003).

It should also be noted that the transition functions from job to job and between unemployment and employment can be easily obtained in equilibrium. Most of these are constant through time. The quit flow from one job to another job, however, decreases with tenure; i.e. at any given firm, there is negative duration dependence in its employees' job-to-job hazard rate. This testable prediction distinguishes our 
approach from the one taken by Bagger et al (2010). In that framework a worker always quits whenever he/she contacts a more productive firm; i.e. at any given firm, its employees' job-to-job hazard rate is duration independent.

Finally we comment on our restriction that the piece rate contract $\theta(\tau)$ is not conditioned on prior experience $x_{0}$; i.e. what happens if we allow more general contracts $\theta=\theta\left(. \mid x_{0}\right)$ ? First note that equation (29), which describes how wages evolve within the employment spell, will continue to hold: it describes the optimal (local) trade-off between smoother wages and reduced quit incentives. The fundamental difference is that if contract offers discriminate by prior experience then the distribution of outside offers is described by $F\left(U \mid x_{0}\right)$. Clearly this extension significantly complicates any equilibrium analysis: it then needs to characterise a continuum of outside offer distributions. Such an extension, however, would have two clear implications. First it implies workers with the same productivity but different prior experience are offered different contracts. Such discrimination is potentially illegal - it allows firms to discriminate against, say, highly talented women who return to the workplace after a spell of child-rearing. Second the wage equation must be extended as

$$
\log w_{i j}\left(x, \tau \mid x_{0}\right)=\log y_{i}+\log \theta_{j}\left(0 \mid x_{0}\right)+\rho x+\log \frac{\theta_{j}\left(\tau \mid x_{0}\right)}{\theta_{j}\left(0 \mid x_{0}\right)}
$$

where $x_{0}$ describes the worker's prior experience at the point of hire. But this equation can be rearranged as

$$
\log \widehat{w}_{i j}\left(\tau, x_{0}\right)=\log y_{i}+\left[\log \theta_{j}\left(0 \mid x_{0}\right)+\rho x_{0}\right]+\left[\log \frac{\theta_{j}\left(\tau \mid x_{0}\right)}{\theta_{j}\left(0 \mid x_{0}\right)}+\rho \tau\right],
$$

where the second term describes the prior experience effect and the last term describes the tenure effect (interacted with prior experience). Clearly identifying the return to experience $\rho$ becomes more problematic with such discrimination.

\section{REFERENCES}

ABOWD, J. M., F. KRAMARZ and D. N. MARGOLIS (1999), "High Wage Workers and High Wage Firms," Econometrica, 67, 251-334.

ABRAHAM, K.G. and H.S. FARBER (1987), "Job Duration, Seniority, and Earnings," American Economic Review, vol. 77, 3, 278-297. 
ALTONJI, J. G. and R. A. SHAKOTKO (1987), "Do Wages Rise With Job Seniority?," Review of Economic Studies, LIV, 437-459.

ALTONJI, J. G. and N. WILLIAMS (1995), "The Effects of Labor Market Experience, Job Seniority and Job Mobility on Wage Growth," NBER Working Paper Series 4133.

BAGGER, J, F. FONTAINE, F. POSTEL-VINAY, and J-M. R0BIN 2006. "A Feasible Equilibrium Search Model of Individual Wage Dynamics with Human Capital Accumulation." http://www.efm.bris.ac.uk/ecfybpv/wp/humancapital.pdf BURDETT, K. (1978) 'A Theory of Employee Job Search and Quit Rate,' American Economic Review, 68(I) 212-20.

BURDETT, K and COLES, M.G. (2003), "Equilibrium Wage/Tenure Contracts," Econometrica, Vol. 71. No. 5 (Sept.) 1377-1404.

BURDETT, K. and MORTENSEN, D.T. (1998), "Wage Differentials, Employer Size,and Unemployment," International Economic Review, 39: 257-273.

DUSTMAN C. and C. MEGHIR (2005), "Wages, Experience, and Seniority," Review of Economic Studies, Vol. 72, No. 1, pp. 77-108, January.

ECKSTEIN, Z. and K.I. WOLPIN (1990), "Estimating a Market Equilibrium Search Model from Panel Data on Individuals," Econometrica 58, 783-808.

HOLZNER, C. (2010), "Optimal Wage Policy with Endogenous search Intensity," mimeo CESifo.

KAMBOROV G. and I MANOVSKII (2005), "Occupational Specificity of Human Capital," Working Paper, University of Pennsylvania, LEONARD, D and N.V. LONG (1992). Optimal Control Theory and Static Optimization in Economics, Cambridge University Press.

MINCER, J. (1974). Schooling, Experience and Earnings. New York: National Bureau of Economic Research.

MORTENSEN, D.T. (2003), Wage Dispersion: Why are Similar People Paid Differently. Cambridge: MIT Press, 2003.

MOSCARINI, G. (2005), "Job Matching and the Wage Distribution" Econometrica, Vol. $73,481-516$. 
POSTEL-VINAY, F., and J.-M. ROBIN (2002a), "The Distribution of Earnings in an Equilibrium Search Model with State-Dependent Offers and Counter-Offers," International Economic Review, 43(4), 989-1016.

POSTEL-VINAY, F., and J.-M. ROBIN (2002b), ""Equilibrium Wage Dispersion with Worker and Employer Heterogeneity.," Econometrica, 70(6), 2295-350.

POSTEL-VINAY, F., and J.-M. ROBIN (2004), "Optimal wage posting with endogenous worker search intensity", Review of Economic Dynamics, 7 (2), 297-330.

ROSEN, S. (1972). "Learning and Experience in the Labor Market." Journal of Human Resources, 7(3): 326-342.

SHI, S. (2009) "Directed Search for Equilibrium Wage-Tenure Contracts", Econometrica, 77,2, 561-84.

STEVENS, M. (2004), "Wage-Tenure Contracts in a Frictional Labour Market: Firms' Strategies for Recruitment and Retention", Review of Economic Studies, v. 71(2), pp 535-551.

TOPEL R. H. (1991), "Specific Capital, Mobility, and Wages: Wages Rise with Job Seniority," Journal of Political Economy," 99, 145-175.

YAMAGUCHI, S. (2006), "Job Search, Bargaining, and Wage Dynamics," mimeo, McMaster University. 


\section{Appendix.}

Proof of Theorem 1. Define $\Phi(t)=e^{\rho t} \psi(t \mid$.$) . The firm's optimal contract solves$

$$
\max _{\theta(.) \geq 0} \int_{0}^{\infty} \Phi(t)[1-\theta(t)] d t
$$

where (1) and (3) in the text imply:

$$
\begin{gathered}
\dot{\Phi}=[\rho-\phi-\delta-\lambda(1-F(U))] \Phi \\
\dot{U}=[\delta+\phi-\rho(1-\sigma)] U-\frac{\theta^{1-\sigma}}{1-\sigma}-\delta U^{U}-\lambda \int_{U}^{\bar{U}}\left[1-F\left(U_{0}\right)\right] d U_{0}
\end{gathered}
$$

and with starting values

$$
\Phi(0)=1 ; U(0)=U_{0}
$$

Define the Hamiltonian

$$
\begin{aligned}
H= & \Phi[1-\theta]+\mu_{\Phi}[\rho-\phi-\delta-\lambda(1-F(U))] \Phi \\
& +\mu_{U}\left[[\delta+\phi-\rho(1-\sigma)] U-\frac{\theta^{1-\sigma}}{1-\sigma}-\delta U^{U}-\lambda \int_{U}^{\bar{U}}\left[1-F\left(U_{0}\right)\right] d U_{0}\right] .
\end{aligned}
$$

where $\mu_{\Phi}, \mu_{U}$ denote the costate variables associated with the state variables $\Phi, U$. Whenever the corner constraint $\theta \geq 0$ is not binding, the Maximum Principle implies the necessary conditions for a maximum are:

$$
\frac{\partial H}{\partial \theta}=-\Phi-\mu_{U} \theta^{-\sigma}=0
$$

and

$$
\frac{d \mu_{\Phi}}{d t}=-[1-\theta(t)]-\mu_{\Phi}[\rho-\phi-\delta-\lambda(1-F(U))]
$$

The standard approach also identifies a differential equation for $\mu_{U}$ but we cannot use that approach as we do not assume $F$ is differentiable. Instead no discounting implies the additional constraint

$$
H=0
$$


(e.g. p298, Leonard and Long (1992)) and this condition is sufficient to establish the Theorem.

Integrating (33) yields:

$$
\begin{aligned}
\mu_{\Phi}(t) & =\int_{t}^{\infty} e^{-\int_{t}^{s}[\delta+\phi-\rho+\lambda(1-F(U(\tau))] d \tau}(1-\theta(s)) d s+A_{0} e^{\int_{0}^{t}[\phi+\delta+\lambda(1-F(V(x)))-\rho] d x} \\
& =\Pi(t)+A_{0} e^{\int_{0}^{t}[\phi+\delta+\lambda(1-F(V(x)))-\rho] d x}
\end{aligned}
$$

where $A_{0}$ is the constant of integration and $\Pi($.$) is the firm's continuation profit as$ defined in the Theorem. As (32) implies $\mu_{U}=-\Phi \theta^{\sigma}$, then substituting out $\mu_{U}$ and $\mu_{\Phi}$ in the definition of $H$, the restriction $\mathrm{H}=0$ yields the optimality condition:

$$
\begin{aligned}
0= & {[1-\theta]+\left[\Pi+A_{0} e^{\left.\int_{0}^{t}[\phi+\delta+\lambda(1-F(U(\tau)))-\rho] d \tau\right]}[\rho-\phi-\delta-\lambda(1-F(U))]\right.} \\
& -\theta^{\sigma}\left[[\delta+\phi-\rho(1-\sigma)] U-\frac{\theta^{1-\sigma}}{1-\sigma}-\delta U^{U}-\lambda \int_{U}^{\bar{U}}\left[1-F\left(U_{0}\right)\right] d U_{0}\right] .
\end{aligned}
$$

Now the restriction $\phi>\rho$ ensures $\exp \left[\int_{0}^{t}[\phi+\delta+\lambda(1-F(U(\tau)))-\rho] d \tau\right]$ grows exponentially as $t \rightarrow \infty$. As $\Pi$ and $U$ must be bounded (otherwise an employee or firm must be willing to make unboundedly large losses) then (34) implies $A_{0}=0$. (34) now yields (5) given in the Theorem. Using this to substitute out $\frac{\theta^{1-\sigma}}{1-\sigma}$ in $(31)$ then yields (7).

Finally note (5) determines $\theta$. As $\theta \rightarrow 0, \sigma>0$ guarantees the left hand side of (5) becomes unboundedly large. As the right hand side of (5) is bounded it follows that $\sigma>0$ implies $\theta \geq 0$ is never a binding constraint. This completes the proof of Theorem 1.

\section{Proof of Lemma 1:}

Lemma 1(a) follows from standard contradiction arguments. $\underline{U}<U^{u}$ is inconsistent with strictly positive profit (firms offering starting value $U_{0}<U^{u}$ make zero profit), while $\underline{U}>U^{u}$ is inconsistent with the constant profit condition (offering $U_{0}=\underline{U}$ is dominated by offering $U_{0}=U^{U}$ as both offers only attract the unemployed and offering $U^{u}<\underline{U}$ generates greater profit per hire). Lemma 1(b) then follows from standard turnover arguments.

Proof of Lemma 2: Consider the pool of employed workers who have experience no greater than $x>0$ and piece rate value no greater than $U$. Then for $U<U^{\infty}$, the 
total outflow of workers from this pool, over any instant of time $d t>0$, is

$$
\begin{aligned}
& (1-\overline{u e}) H(x, U)\left[\phi+\delta+\lambda(1-F(U)] d t+(1-\overline{u e}) \int_{U^{\prime}=\underline{U}}^{U} \int_{x^{\prime}=x-d t}^{x} \frac{\partial^{2} H}{\partial U \partial x} d U^{\prime} d x^{\prime}\right. \\
& +(1-\overline{u e}) \int_{U^{\prime}=U^{s}(t-d t)}^{U^{s}(t)} \int_{x^{\prime}=0}^{x} \frac{\partial^{2} H}{\partial U \partial x} d U^{\prime} d x^{\prime}+O\left(d t^{2}\right),
\end{aligned}
$$

where the first term is the number who die, lose their job or quit through receiving a job offer with value greater than $U$, the second is the number who exit through achieving greater experience, while the third is the number who exit through internal promotion, where $U^{s}(t)=U$. The inflow is $\lambda \overline{u e} F(U) N(x) d t$ which is the number of unemployed workers with experience no greater than $\mathrm{x}$ who receive a job offer with value no greater than $U$. Setting inflow equal to outflow, using the solution for $\overline{u e}$ in lemma 1 and letting $d t \rightarrow 0$ implies $H$ satisfies:

$$
\begin{aligned}
& H(x, U)\left[\phi+\delta+\lambda(1-F(U)]+\int_{U^{\prime}=\underline{U}}^{U} \frac{\partial^{2} H}{\partial U \partial x} d U^{\prime}\right. \\
& +\dot{U} \int_{x^{\prime}=0}^{x} \frac{\partial^{2} H}{\partial U \partial x} d x^{\prime}=(\phi+\delta) F(U) N(x) .
\end{aligned}
$$

Integrating thus yields

$$
\begin{aligned}
& H(x, U)\left[\phi+\delta+\lambda(1-F(U)]+\left[\frac{\partial H[x, U]}{\partial x}-\frac{\partial H[x, \underline{U}]}{\partial x}\right]\right. \\
& +\dot{U}\left[\frac{\partial H[x, U]}{\partial U}-\frac{\partial H[0, U]}{\partial U}\right]=(\phi+\delta) F(U) N(x) .
\end{aligned}
$$

But $H(0, U)=H(x, \underline{U})=0$ implies $\frac{\partial H[x, \underline{U}]}{\partial x}=\frac{\partial H[0, U]}{\partial U}=0$ which with the above equation yields the stated solution. This argument but for $U>U^{\infty}$ establishes the same differential equation. This completes the proof of Lemma 2.

Proof of Theorem 2. The central step is to solve for

$$
\int_{x^{\prime}=0}^{\infty} \int_{U^{\prime}=\underline{U}}^{U_{0}} e^{\rho x^{\prime}} \frac{\partial^{2} H\left(x^{\prime}, U^{\prime}\right)}{\partial x \partial U^{\prime}} d x^{\prime} d U^{\prime}
$$

with $H($.$) as described by Lemma 2$. 
First note that as the measure of employed workers with no experience is zero, then

$$
\begin{aligned}
\int_{x^{\prime}=0}^{\infty} \int_{U^{\prime}=\underline{U}}^{U_{0}} e^{\rho x^{\prime}} \frac{\partial^{2} H\left(x^{\prime}, U^{\prime}\right)}{\partial x \partial U^{\prime}} d x^{\prime} d U^{\prime} & =\int_{x^{\prime}>0} e^{\rho x^{\prime}}\left[\int_{U^{\prime}=\underline{U}}^{U_{0}} \frac{\partial^{2} H\left(x^{\prime}, U^{\prime}\right)}{\partial x \partial U^{\prime}} d U^{\prime}\right] d x^{\prime} \\
& =\int_{x^{\prime}>0} e^{\rho x^{\prime}} \frac{\partial H\left(x^{\prime}, U_{0}\right)}{\partial x} d x^{\prime} .
\end{aligned}
$$

as $H_{x}\left(x^{\prime}, \underline{U}\right)=0$. Thus $(21)$ implies

$$
\widehat{\Pi}\left(U_{0}\right)\left[\frac{\phi(\phi+\delta-\rho)}{\phi(\phi+\delta+\lambda)-\rho(\phi+\lambda)}+\frac{\lambda}{\lambda+\phi+\delta} \int_{x^{\prime}>0} e^{\rho x^{\prime}} \frac{\partial H\left(x^{\prime}, U_{0}\right)}{\partial x} d x^{\prime}\right]=\frac{\bar{\Omega}}{\lambda y_{0}}
$$

for all $U_{0} \in[\underline{U}, \bar{U}]$. Differentiating wrt $U_{0}$ implies

$$
\left[\begin{array}{c}
\frac{d \widehat{\Pi}}{d U}\left[\frac{\phi(\phi+\delta-\rho)}{\phi(\phi+\delta+\lambda)-\rho(\phi+\lambda)}+\frac{\lambda}{\lambda+\phi+\delta} \int_{x^{\prime}>0} e^{\rho x^{\prime}} \frac{\partial H\left(x^{\prime}, U_{0}\right)}{\partial x} d x^{\prime}\right] \\
+\widehat{\Pi}\left[\frac{\lambda}{\lambda+\phi+\delta} \int_{x^{\prime}>0} e^{\rho x^{\prime}} \frac{\partial^{2} H\left(x^{\prime}, U_{0}\right)}{\partial x \partial U} d x^{\prime}\right]
\end{array}\right]=0 \text { for all } U_{0} \in[\underline{U}, \bar{U}] .
$$

Consider now the integral in the second line. For $x>0$, partial differentiation with respect to $x$ of the pde for $H$, given by lemma 2 , implies

$$
\dot{U} \frac{\partial^{2} H}{\partial x \partial U}=(\phi+\delta) F N^{\prime}(x)-\left[[\phi+\delta+\lambda(1-F)] \frac{\partial H}{\partial x}+\frac{\partial^{2} H}{\partial x^{2}}\right],
$$

where $\dot{U}=\dot{U}(U)$ is given by (20). Thus

$$
\int_{x^{\prime}>0} e^{\rho x^{\prime}} \frac{\partial^{2} H\left(x^{\prime}, U_{0}\right)}{\partial x \partial U} d x^{\prime}=\frac{1}{\dot{U}} \int_{x^{\prime}>0} e^{\rho x^{\prime}}\left[(\phi+\delta) F N^{\prime}(x)-\left[[\phi+\delta+\lambda(1-F)] \frac{\partial H}{\partial x}+\frac{\partial^{2} H}{\partial x^{2}}\right]\right] d x^{\prime} .
$$

Straightforward algebra using (18) finds

$$
\int_{x^{\prime}>0} e^{\rho x^{\prime}}(\phi+\delta) F N^{\prime}(x) d x=\frac{\phi \lambda \delta(\phi+\delta+\lambda) F}{(\phi+\lambda)[\phi(\phi+\delta+\lambda)-\rho(\phi+\lambda)]}
$$

The second term in (37) is computed as follows:

$$
\begin{aligned}
& \int_{x^{\prime}>0} e^{\rho x^{\prime}}\left[[\phi+\delta+\lambda(1-F)] \frac{\partial H}{\partial x}+\frac{\partial^{2} H}{\partial x^{2}}\right] d x^{\prime} \\
= & \int_{x^{\prime}>0} e^{[\rho-[\phi+\delta+\lambda(1-F)]] x^{\prime}}\left\{e^{[\phi+\delta+\lambda(1-F)] x^{\prime}}\left[[\phi+\delta+\lambda(1-F)] \frac{\partial H}{\partial x}+\frac{\partial^{2} H}{\partial x^{2}}\right]\right\} d x^{\prime} \\
= & {\left[e^{\rho x^{\prime}} \frac{\partial H\left(x^{\prime}, U_{0}\right)}{\partial x}\right]_{0^{+}}^{\infty}-\int_{x^{\prime}>0}[\rho-[\phi+\delta+\lambda(1-F)]] e^{\rho x^{\prime}} \frac{\partial H\left(x^{\prime}, U_{0}\right)}{\partial x} d x^{\prime} }
\end{aligned}
$$


Putting $x=0$ in the pde for $H$ (see Lemma 2) implies

$$
\frac{\partial H(0, U)}{\partial x}=(\phi+\delta) N_{0} F(U)
$$

Now as $x^{\prime} \rightarrow \infty$, the conditional distribution of employee payoffs $H\left(U \mid x^{\prime}\right)$ converges to its ergodic distribution $H(U \mid \infty)$. As the distribution of experience is exponential with parameter $\phi(\phi+\delta+\lambda) /(\phi+\lambda)$ [see equation (19) in the text] then $\phi>\rho$ guarantees $\lim _{x^{\prime} \rightarrow \infty} \exp \left(\rho x^{\prime}\right) \partial H / \partial x=0$. Thus we obtain:

$$
\begin{aligned}
& \int_{x^{\prime}>0} e^{\rho x^{\prime}}\left[[\phi+\delta+\lambda(1-F)] \frac{\partial H}{\partial x}+\frac{\partial^{2} H}{\partial x^{2}}\right] d x^{\prime} \\
= & {[\phi+\delta-\rho+\lambda(1-F)] \int_{x^{\prime}>0} e^{\rho x^{\prime}} \frac{\partial H\left(x^{\prime}, U_{0}\right)}{\partial x} d x^{\prime}-(\phi+\delta) N_{0} F } \\
= & {[\phi+\delta-\rho+\lambda(1-F)] \int_{x^{\prime}>0} e^{\rho x^{\prime}} \frac{\partial H\left(x^{\prime}, U_{0}\right)}{\partial x} d x^{\prime}-\frac{\phi(\phi+\lambda+\delta)}{\phi+\lambda} F }
\end{aligned}
$$

by definition of $N_{0}$ and (18). Inserting this solution into (37) yields an equation for $\int_{x^{\prime}>0} e^{\rho x^{\prime}} \frac{\partial^{2} H\left(x^{\prime}, U_{0}\right)}{\partial x \partial U} d x^{\prime}$. Using that equation to substitute out $\int_{x^{\prime}>0} e^{\rho x^{\prime}} \frac{\partial^{2} H\left(x^{\prime}, U_{0}\right)}{\partial x \partial U} d x^{\prime}$ in (36) then yields a closed form solution for $\int_{x^{\prime}>0} e^{\rho x^{\prime}} \frac{\partial H\left(x^{\prime}, U_{0}\right)}{\partial x} d x^{\prime}$. Using this expression for $\int_{x^{\prime}>0} e^{\rho x^{\prime}} \frac{\partial H\left(x^{\prime}, U_{0}\right)}{\partial x} d x^{\prime}$ in (35) and simplifying, the constant profit condition reduces (miraculously) to

$$
\widehat{\Pi}^{2}=\frac{[\phi(\phi+\delta+\lambda)-\rho(\phi+\lambda)] \bar{\Omega}}{\phi(\phi+\delta-\rho)[\delta+\phi-\rho+\lambda] \lambda y_{0}}(1-\widehat{\theta}) \text { for all } U_{0} \in[\underline{U}, \bar{U}] .
$$

Finally we substitute out $\bar{\Omega}$ in this expression. Putting $U_{0}=\bar{U}$ in (35), letting $\bar{\Pi} \equiv \widehat{\Pi}(\bar{U})$, substituting out $H(x, \bar{U})$ using (19) and some algebra establishes

$$
\bar{\Pi}\left[\frac{\phi(\phi+\delta-\rho+\lambda)}{\phi(\phi+\delta+\lambda)-\rho(\phi+\lambda)}\right]=\frac{\bar{\Omega}}{\lambda y_{0}} .
$$

Substituting out $\bar{\Omega}$ in the previous equation now yields

$$
\widehat{\Pi}^{2}=\frac{\bar{\Pi}}{(\phi+\delta-\rho)}(1-\widehat{\theta}) \text { for all } U_{0} \in[\underline{U}, \bar{U}] .
$$

Setting $U_{0}=\bar{U}$ implies

$$
\bar{\Pi}=\frac{1-\bar{\theta}}{\phi+\delta-\rho}
$$


and combining the last two expressions yields the Theorem. This completes the proof of Theorem 2.

Proof of Lemma 3. Using Theorem 2 to compute $d \widehat{\Pi} / d U$ and using (14) in Claim 1 implies $\widehat{\theta}($.$) satisfies$

$$
\frac{\phi(\phi+\delta-\rho)+\lambda \phi}{2 \phi(\phi+\delta-\rho)[\delta+\phi-\rho+\lambda]} \sqrt{(1-\bar{\theta})}(1-\widehat{\theta})^{-1 / 2} \widehat{\theta}^{-\sigma} \frac{d \widehat{\theta}}{d U}=1
$$

with $\widehat{\theta}=\bar{\theta}$ at $U=\bar{U}$. Integrating implies (23). Putting $U=\bar{U}$ in (15) and using (39) in the Appendix implies (24). Noting $\partial H(x, \underline{U}) / \partial x=0$, then putting $U=\underline{U}$ in (35) and using (38), (39) and Theorem 2 yields (25). Finally putting $U=\underline{U}$ in (23) implies (24). This completes the proof of Lemma 3.

Proof of Theorem 3: By construction these are necessary conditions for a Market Equilibrium. Given any such solution, then by construction all optimal contracts which offer $U_{0} \in[\underline{U}, \bar{U}]$ yield the same steady state flow profit. Consider now any deviating contract. Clearly, a suboptimal contract which offers $U_{0} \in[\underline{U}, \bar{U}]$ yields lower profit. Further any contract which offers value $U_{0}<\underline{U}$ yields zero profit as $U^{U}=\underline{U}$ and all workers reject such an offer. Finally any contract which offers $U_{0}>\bar{U}$ attracts no more workers than an optimal contract which offers $\bar{U}$ while the latter contract earns strictly greater profit per hire. ${ }^{6}$ As no deviating contracts exist which yield greater profit, a solution to the above conditions identifies a Market Equilibrium.

We now establish existence of a solution when $\sigma>0$. Given an arbitrary value for $\bar{\theta} \in\left(1-\left[\frac{\phi+\delta-\rho}{\phi+\delta-\rho+\lambda}\right]^{2}, 1\right)$, let $\widetilde{F}(. \mid \bar{\theta})$ denote the solution for $F$ implied by solving parts A,B of Theorem 3 above. Further define $\widetilde{U}^{U}(\bar{\theta})$ as the solution for $U^{U}$ where

$$
\phi U^{U}=\frac{b^{1-\sigma}}{1-\sigma}+\lambda \int_{U^{U}}^{\bar{U}}[1-\widetilde{F}(. \mid \bar{\theta})] d U_{0}
$$

i.e. $\widetilde{U}^{U}(\bar{\theta})$ is the optimal reservation piece rate $U^{U}$ of unemployed workers given offer distribution $\widetilde{F}(. \mid \bar{\theta})$. A Market Equilibrium requires finding a $\bar{\theta} \in\left(1-\left[\frac{\phi+\delta-\rho}{\phi+\delta-\rho+\lambda}\right]^{2}, 1\right)$ such that $\widetilde{U}^{U}(\bar{\theta})=\underline{U}(\bar{\theta})$.

\footnotetext{
${ }^{6}$ Note the arguments in Burdett and Coles (2003) rule out a mass point in $H$ at $U=\bar{U}$.
} 
First note that as $\bar{\theta} \rightarrow 1,(25)$ implies $\underline{\theta} \rightarrow 1$. As all piece rates $\theta$ paid must then lie in an arbitrarily small neighborhood around one, frictions $(\lambda<\infty)$ and $b<1$ imply $\widetilde{U}^{U}<\underline{U}$. Instead consider the limit $\bar{\theta} \rightarrow \lambda(\lambda+2[\phi+\delta-\rho]) /(\phi+\delta-\rho+\lambda)^{2}$ which, by (25), implies $\underline{\theta} \rightarrow 0 . \sigma \geq 1$ implies the flow payoff by accepting the lowest $\underline{\theta}$ offer, $\underline{\theta}^{1-\sigma} /(1-\sigma)$, becomes unboundedly negative in this limit. As $\widehat{\theta}($.$) is continuous and is$ less than $\bar{\theta}$, this implies $\underline{U} \rightarrow-\infty$ in this limit. But (40) implies $\phi \widetilde{U}^{U}>\frac{b^{1-\sigma}}{1-\sigma}$ and thus $\widetilde{U}^{U}>\underline{U}$ in this limit. As the solutions for $\widehat{\theta}(),. \widehat{\Pi}(),. S($.$) and \underline{U}$ are all continuous in $\bar{\theta}$, continuity now implies a $\bar{\theta} \in\left(1-\left[\frac{\phi+\delta-\rho}{\phi+\delta-\rho+\lambda}\right]^{2}, 1\right)$ exists where $\widetilde{U}^{U}=\underline{U}$ and so identifies a Market Equilibrium. This completes the proof of Theorem 3. 


\section{CESifo Working Paper Series}

for full list see www.cesifo-group.org/wp

(address: Poschingerstr. 5, 81679 Munich, Germany, office@cesifo.de)

3140 Lawrence M. Kahn, Labor Market Policy: A Comparative View on the Costs and Benefits of Labor Market Flexibility, July 2010

3141 Ben J. Heijdra, Jochen O. Mierau and Laurie S.M. Reijnders, The Tragedy of Annuitization, July 2010

3142 Erkki Koskela, Outsourcing Cost and Tax Progression under Nash Wage Bargaining with Flexible Outsourcing, July 2010

3143 Daniel Osberghaus and Christiane Reif, Total Costs and Budgetary Effects of Adaptation to Climate Change: An Assessment for the European Union, August 2010

3144 Philip E. Graves, Benefit-Cost Analysis of Environmental Projects: A Plethora of Systematic Biases, August 2010

3145 Sabrina Di Addario and Daniela Vuri, Entrepreneurship and Market Size. The Case of Young College Graduates in Italy, August 2010

3146 Shoshana Amyra Grossbard and Alfredo Marvăo Pereira, Will Women Save more than Men? A Theoretical Model of Savings and Marriage, August 2010

3147 Jarko Fidrmuc, Time-Varying Exchange Rate Basket in China from 2005 to 2009, August 2010

3148 Ilja Neustadt and Peter Zweifel, Is the Welfare State Sustainable? Experimental Evidence on Citizens' Preferences for Redistribution, August 2010

3149 Marcus Dittrich and Andreas Knabe, Wage and Employment Effects of Non-Binding Minimum Wages, August 2010

3150 Shutao Cao, Enchuan Shao and Pedro Silos, Fixed-Term and Permanent Employment Contracts: Theory and Evidence, August 2010

3151 Ludger Woessmann, Cross-Country Evidence on Teacher Performance Pay, August 2010

3152 Lorenzo C. G. Pozzi, Casper G. de Vries and Jorn Zenhorst, World Equity Premium Based Risk Aversion Estimates, August 2010

3153 Volker Grossmann, Thomas M. Steger and Timo Trimborn, Dynamically Optimal R\&D Subsidization, August 2010

3154 Alexander Haupt, Tim Krieger and Thomas Lange, A Note on Brain Gain and Brain Drain: Permanent Migration and Education Policy, August 2010 
3155 António Afonso and Christophe Rault, Long-run Determinants of Sovereign Yields, August 2010

3156 Franziska Tausch, Jan Potters and Arno Riedl, Preferences for Redistribution and Pensions. What can we Learn from Experiments?, August 2010

3157 Martin Kolmar and Andreas Wagener, Inefficient Group Organization as Optimal Adaption to Dominant Environments, August 2010

3158 Kai Carstensen, Klaus Wohlrabe and Christina Ziegler, Predictive Ability of Business Cycle Indicators under Test: A Case Study for the Euro Area Industrial Production, August 2010

3159 Horst Rottmann and Timo Wollmershäuser, A Micro Data Approach to the Identification of Credit Crunches, August 2010

3160 Philip E. Graves, Appropriate Fiscal Policy over the Business Cycle: Proper Stimulus Policies Can Work, August 2010

3161 Michael Binder and Marcel Bluhm, On the Conditional Effects of IMF Program Participation on Output Growth, August 2010

3162 Michael Binder, Qianying Chen, and Xuan Zhang, On the Effects of Monetary Policy Shocks on Exchange Rates, August 2010

3163 Felix J. Bierbrauer, On the Optimality of Optimal Income Taxation, August 2010

3164 Nikolaus Wolf, Europe's Great Depression - Coordination Failure after the First World War, September 2010

3165 Dan Kovenock and Brian Roberson, Conflicts with Multiple Battlefields, September 2010

3166 Jean-Pierre Ponssard and Catherine Thomas, Capacity Investment under Demand Uncertainty. An Empirical Study of the US Cement Industry, 1994-2006, September 2010

3167 Jørgen Juel Andersen, Jon H. Fiva and Gisle James Natvik, Voting when the Stakes are High, September 2010

3168 Michael Hoel, Is there a Green Paradox?, September 2010

3169 Scott Alan Carson, Nineteenth Century US African-American and White Female Statures: Insight from US Prison Records, September 2010

3170 Gil S. Epstein, Yosef Mealem and Shmuel Nitzan, Political Culture and Discrimination in Contests, September 2010

3171 Sara Fisher Ellison, Jeffrey Greenbaum and Wallace P. Mullin, Diversity, Social Goods Provision, and Performance in the Firm, September 2010 
3172 Silvia Dominguez-Martinez, Randolph Sloof and Ferdinand von Siemens, Monitoring your Friends, not your Foes: Strategic Ignorance and the Delegation of Real Authority, September 2010

3173 Marcus Dittrich and Beate Schirwitz, Union Membership and Employment Dynamics: A Note, September 2010

3174 Francesco Daveri, Paolo Manasse and Danila Serra, The Twin Effects of Globalization - Evidence from a Sample of Indian Manufacturing Firms, September 2010

3175 Florian Blöchl, Fabian J. Theis, Fernando Vega-Redondo and Eric O’N. Fisher, Which Sectors of a Modern Economy are most Central?, September 2010

3176 Dag Morten Dalen, Marilena Locatelli and Steinar Strøm, Longitudinal Analysis of Generic Substitution, September 2010

3177 Armin Falk, Stephan Meier and Christian Zehnder, Did we Overestimate the Role of Social Preferences? The Case of Self-Selected Student Samples, September 2010

3178 Christian Fahrholz and Cezary Wójcik, The Bail-Out! Positive Political Economics of Greek-type Crises in the EMU, September 2010

3179 Klaus Abberger and Wolfgang Nierhaus, The Ifo Business Cycle Clock: Circular Correlation with the Real GDP, September 2010

3180 Walter Krämer and Gerhard Arminger, "True Believers" or Numerical Terrorism at the Nuclear Power Plant, September 2010

3181 Bernard M.S. Van Praag, Dmitri Romanov and Ada Ferrer-i-Carbonell, Happiness and Financial Satisfaction in Israel. Effects of Religiosity, Ethnicity, and War, September 2010

3182 Dimitrios Koumparoulis and Paul De Grauwe, Public Capital, Employment and Productivity: An Empirical Investigation for Greece, September 2010

3183 John Whalley and Tanmaya Shekhar, The Rapidly Deepening India-China Economic Relationship, September 2010

3184 Andreas Schäfer and Thomas Steger, History, Expectations, and Public Policy: Economic Development in Eastern Germany, September 2010

3185 Thomas Eichner and Marco Runkel, Subsidizing Renewable Energy under Capital Mobility, September 2010

3186 Konstantinos Angelopoulos and James Malley, Fear of Model Misspecification and the Robustness Premium, September 2010

3187 Philip E. Graves, A Note on the Design of Experiments Involving Public Goods, September 2010 
3188 Glenn Ellison, How does the Market Use Citation Data? The Hirsch Index in Economics, September 2010

3189 Barbara Hanel and Regina T. Riphahn, The Employment of Mothers - Recent Developments and their Determinants in East and West Germany, September 2010

3190 Alexander Haupt and Silke Uebelmesser, Integration, Mobility, and Human Capital Formation, September 2010

3191 Vincenzo Galasso and Paola Profeta, When the State Mirrors the Family: The Design of Pension Systems, September 2010

3192 Stéphane Zuber and Geir B. Asheim, Justifying Social Discounting: The RankDiscounted Utilitarian Approach, September 2010

3193 Alexander Kemnitz, Educational Federalism and the Quality Effects of Tuition Fees, September 2010

3194 Claudia M. Buch, Sandra Eickmeier and Esteban Prieto, Macroeconomic Factors and Micro-Level Bank Risk, September 2010

3195 May Elsayyad and Kai A. Konrad, Fighting Multiple Tax Havens, September 2010

3196 Laszlo Goerke and Markus Pannenberg, Trade Union Membership and Dismissals, September 2010

3197 Ferdinand Mittermaier and Johannes Rincke, Do Countries Compensate Firms for International Wage Differentials?, September 2010

3198 John Boyd, Gianni De Nicoló and Abu M. Jalal, Bank Competition, Asset Allocations and Risk of Failure: An Empirical Investigation, September 2010

3199 Guido Heineck and Bernd Süssmuth, A Different Look at Lenin's Legacy: Trust, Risk, Fairness and Cooperativeness in the two Germanies, September 2010

3200 Ingvild Almås, Tarjei Havnes and Magne Mogstad, Baby Booming Inequality? Demographic Change and Earnings Inequality in Norway, 1967-2000, October 2010

3201 Thomas Aronsson and Sören Blomquist, The Standard Deviation of Life-Length, Retirement Incentives, and Optimal Pension Design, October 2010

3202 Thorvaldur Gylfason and Eduard Hochreiter, Growing Together: Croatia and Latvia, October 2010

3203 Ken Burdett and Melvyn Coles, Tenure and Experience Effects on Wages: A Theory, October 2010 